\title{
Modelling and Control of a VIENNA Smart Rectifier-I for Wind Power Systems Integrated Under Transient Conditions
}

\author{
Inas M. O. Mohammed ${ }^{1} \cdot$ Michael Njoroge Gitau $^{1} \cdot$ Ramesh C. Bansal $^{2}$ (1) $\cdot$ Kabeya Musasa $^{3}$
}

Received: 2 May 2018 / Accepted: 13 November 2018 / Published online: 3 January 2019

(C) Springer Nature Singapore Pte Ltd. 2019

\begin{abstract}
An improved topology with a fault ride through (FRT) capability when subjected to a DC-link fault-based wind power plant (WPP) employing a Vienna active rectifier-I is proposed in this paper. The proposed system is capable of mitigating fault occurring on the DC-link side using the PWM-controller technique implemented on the Vienna active rectifier. FRT capability analysis is conducted in this paper, simulation results demonstrate the suitability of the control strategy. Actually, use of proposed wind energy conversion unit (WECU) topology has led to the improvement of system stability by maintaining constant output voltage. Furthermore, the WECU integrating Vienna active rectifier-I is also proven as a feasible technology that can be employed in a large-scale WPP or renewable power generations to realize technical and economical efficient grids integration with high voltage direct current (HVDC) transmission systems.
\end{abstract}

Keywords Voltage control · Fault ride through · Vienna rectifier · Wind power · Transient stability · DC collection grid . Fault clearance $\cdot$ Smart rectifiers

\section{Introduction}

Due to the increased demand of electricity nowadays, the world is moving towards the use of renewable energy sources because of high efficiency, resource availability, cost competitiveness and environmental adequateness. In this respect, recent researches have been developed towards the improvement of renewable energy technology [1-3]. In fact, for an $\mathrm{AC}$ collection grid, each wind energy conversion system (WECS) on a WPP includes: a windturbine plus mechanical parts (e.g. gearbox), a generator (e.g. doubly fed induction generator (DFIG), permanent magnet synchronous generator (PMSG), squirrel cage induction generator (SCIG)), and a huge $50-$ or $60 \mathrm{~Hz}$

Ramesh C. Bansal

rcbansal@ieee.org

1 Department of Electrical, Electronic and Computer Engineering, University of Pretoria, Pretoria, South Africa

2 Department of Electrical and Computer Engineering, University of Sharjah, Sharjah, United Arab Emirates

3 Department of Electrical Power Engineering, Durban University of Technology, Durban, South Africa power transformer including controller circuit. In this paper a wind farm with DC collection grid is considered. For a wind farm employing DC collection grid, the huge power transformers in the WECSs are replaced by the power electronic converters. The power electronic converter is significantly compact and small in size compared to the power transformer of identical features.

Most of studies being done on the design of DC collection grids for wind farm employ the conventional full-bridge active rectifiers as the topology of power converters in WECS. The conventional full-bridge active rectifier contain large numbers of controlled-switches, which increase complexity of controller circuit and affect the system efficiency because of the high switching frequency operation of the controlled switch. The wind DC collection grid in this paper is built out using the parallel connection of Vienna-I active rectifier, and thus reduces the numbers of controlled switches in the power converter compared with conventional active rectifiers.

The DC technology has acquired significant applications in modern distribution systems due to the high penetration levels of DC loads and DC-based distributed generators (DGs) [1]. Unlike conventional AC distribution systems, DC distribution systems have high penetration level of power converters used to interface both DGs and loads [2]. 
HVDC power transmission and distribution systems have received wide acceptance in power systems and renewable energy resources integration technology. Moreover, DC systems present more advantages over the AC systems. For example, the synchronization of multiple generators, which is flexible because of no frequency sharing than that of AC system, also the absence of reactive power in DC-link increase the system stability [3]. It is also easy to integrate the renewable energy sources into DC grid using simplified control scheme at low cost. As the number of grid-connected wind farms is constantly increasing, the WPPs have to play a considerable function in maintaining the grid stability [4]. This requires that the wind-turbinegenerators on wind farm stay connected to the power grid for any fault conditions [3]. The FRT is the capability of WECS to stay connected in short periods of fault conditions. This term can also be used to explain the ability of a wind farm to participate to the voltage stability during grid faults [1]. A WPP generally consists of large number of WECS interconnected together either in series, radial, or series-parallel, and injected to a main bus. The generator in WECS is either the SCIG, mostly used for fixed speed windturbine, or a DFIG mostly employed for variable speed wind-turbine (not allow more than $30 \%$ speed variation). Fixed speed wind-turbine do not employ power converter in WECS, the control of parameters (e.g. voltage, current, frequency) output of SCIG is done using the STATCOM or FACTS devices installed on the grid side [1]. The drawback of this topology is that no tracking of maximum wind power mechanism is provided. However for the variable speed wind-turbine, power electronic converter is employed in the WECS circuit. DFIG and PMSG are the most considered type of generators for the WECS based variable speed windturbine synchronous generators, for many advantages, they can supply constant load for the power consumers, and also can monitoring the power rapidly and flexibly with the help of active power electronic convertors [2, 3]. One of the major challenge in WECS is to handle the discontinuity of wind and to protect the grid stability. The power electronics and energy storage systems are substantial components to maintain continuation of wind power. WECUs are basically grouped into two types.

1. Fixed speed WECU: the wind-turbine with a SCIG.

2. Variable speed WECU: this group is classified into two types:

(i) PMSG based wind-turbine with a full rating converter.

(ii) DFIG based wind-turbine with a partial rating converter.
The full rating converters disconnect the synchronous machine speed from the grid frequency and provide adaptable operation over a wide range of speed.

The conventional converters have the following demerits: (i) These are either a buck or a boost converter, (ii) are sensitive to electromagnetic interference (EMI), which reduces the reliability [4, 5]. FRT capability is the ability of WPP to stay connected to the grid while fault is occurring [6-8], and the PMSG is a very suitable choice that can integrate with the wind turbine for the following reasons [9].

1. Can ride-through several grid-faults.

2. Able to cut out from the grid immediately in case of a fault and resume rapidly in normal operation after the fault.

3. Has the capability to smooth out the intermittent power fluctuation from the wind.

Vienna active rectifier-I, originally introduced by Kolar [10], is one of several types of converters that can be selected as a generator side convertor for wind energy conversion systems. The Vienna active rectifier-I is considered to be a convenient and cost-effective and that recognizes the requirements of power quality and power consistency applications. Also it has less number of active semiconductor devices and less voltage stress compared with conventional rectifiers because the output capacitor is divided in two sections with two equivalent values (C1and $\mathrm{C} 2$ ) as shown in Fig. 1. It has low current total harmonic distortion (THD) and high power density because of three switches which are based on three-level configurations. Therefore, it has been used in several high voltage and high power applications [10-14]. The schematic diagram of a three-phase Vienna active rectifier-I is shown in Fig. 1.

It consists of three identical power electronic legs, each one connected separately to a phase input. Each power cell

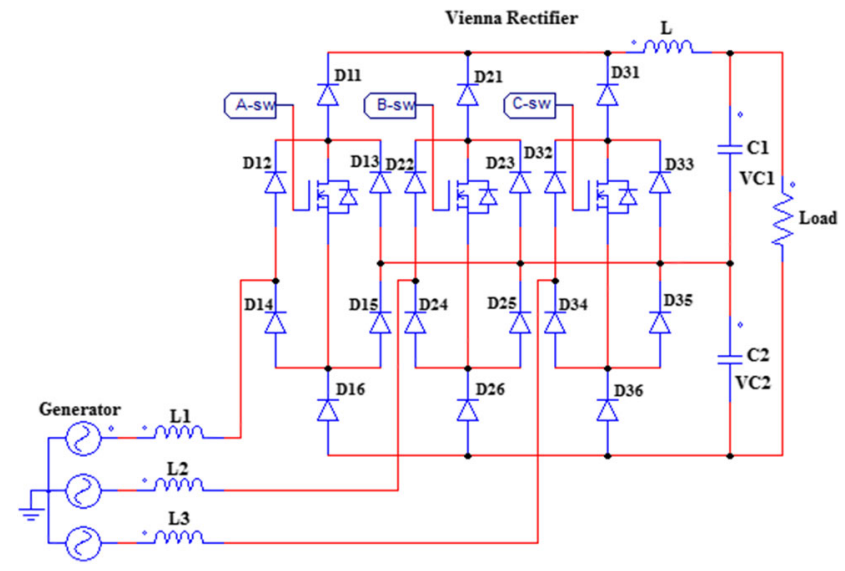

Fig. 1 Three-phase Vienna active Rectifier-I topology 
includes one active switch (e.g. MOSFET) and six diodes, the output of all the stages are connected to a middle point with output capacitors. The midpoint of the capacitors is practically clamped to a neutral point by connecting it to mid-points of one arm of the diode bridges of all the three phases, by this connection three possibilities of output voltage can be obtained, otherwise it can left free [1518]. Vienna active rectifier-I has many advantages over conventional and other types of active rectifiers such as:

1. Capability of double boosting effect because it consists of two inductors, which can improve the rectifier features.

2. Ability of buck-boost operation.

3. Allows transmitting the power to the DC capacitors even if the supply voltage is positive or negative.

4. Involvement of a single switch per power cell that permits to construct a high stable and reliable rectifier.

5. While it is usually used for a three-phase rectification, it can also be used for a single phase applications.

6. Ability of obtaining a two DC-output voltages so that DC-ripples decrease for a given capacitor value.

7. It has the possibility of continuous current and power factor correction operation modes.

However, the disadvantage of using this topology is the difficulty of implementing two inductors [19]. Remaining part of this article is organized as follows. "Modelling and Control of a Vienna Active Rectifier-I" presents modelling and control of Vienna active rectifier-I including rectifier analysis and design of the rectifier input side filter. The AC-bus controller design including design equations and investigation for stability using bode plots have been presented in details in "Design Criteria of the Rectifier Controller". "Fault Effect Elimination and Analysis" discusses the fault effect elimination and analysis which discusses the type of connection and the controller that has been used for ride through the fault. Simulation results and discussions are presented in "Simulation results and Discussions" Conclusion of the paper is presented in "Conclusion".

\section{Modelling and Control of a Vienna Active Rectifier-I}

\section{The Rectifier Analysis}

The converter topology has been shown in Fig. 1. There are three levels of output voltage, $V_{C 1}$ and $V_{C 2}$ each is half of the total output voltage. And the third level is the total $\left(V_{C 1}+V_{C 2}\right)$ and should be greater than the maximum supply voltage. It is a boost converter, because the switching frequency is too high compared with the supply frequency,

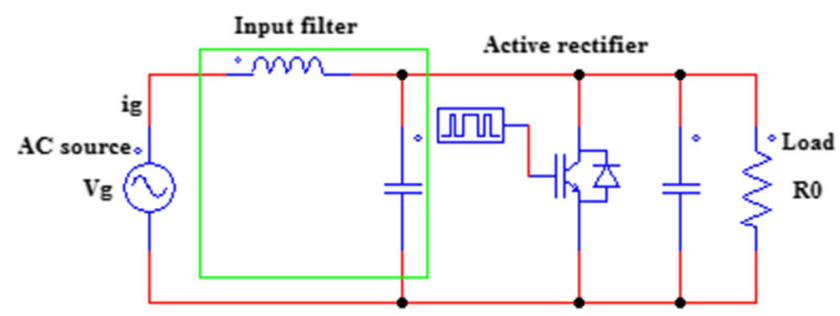

Fig. 2 AC/DC Boost converter circuit [22]

and the output voltage is always greater than the input voltage. The converter injects ripple in the generator, so ripple filter should be considered in the converter input side design. The operation details of the considered converter have been explained in [11-13]. It consists of three active switches (IGBT or MOSFET) and eighteen diodes. The control of the three switches ensures sinusoidal waves input current and desired balanced output DC voltage. The output voltage of the considered rectifier depends on the polarity of the input AC current as well as the switching states [12, 19-21].

\section{Filter Design}

A filter must be added in the converter input side to attenuate the current harmonics that are produced by the switching converter. The converter injects the input current $i_{g}$ into the power source $V_{g}$ as shown in Fig. 2.

The filter also attenuates the EMI and hence enhances the system stability by protecting the converter from transient voltages and currents [22].

\section{Inductor Design}

Inductors are connected in series with a converter input side and can be designed using Eq. 1 .

$L=\frac{V_{\text {in }}\left(V_{\text {out }}-V_{\text {in }}\right)}{\Delta I_{L} * f_{\text {sw }} * V_{\text {out }}}$

By substituting in Eq. 1 and make use of parameters given in Table 1, the value of inductance will be $82 \mathrm{mH}$.

Table 1 Parameters used for filter design

\begin{tabular}{lll}
\hline Parameter & Description & Value \\
\hline Generator rms voltage & $V_{\text {rms }}$ & $500 \mathrm{~V}$ \\
Rectifier output voltage & $V_{\text {out }}$ & $2400 \mathrm{~V}$ \\
Switching frequency & $f_{\text {sw }}$ & $4 \mathrm{kHz}$ \\
Desired output current ripple & $\Delta I_{\text {out }}$ & $1.2 \mathrm{~A}$ \\
Duty ratio & $\mathrm{D}$ & 0.8 \\
Desired output voltage ripple & $\Delta V_{\text {out }}$ & $48 \mathrm{~V}$ \\
Rectifier output current & $I_{\text {out }}$ & $50 \mathrm{~A}$ \\
\hline
\end{tabular}




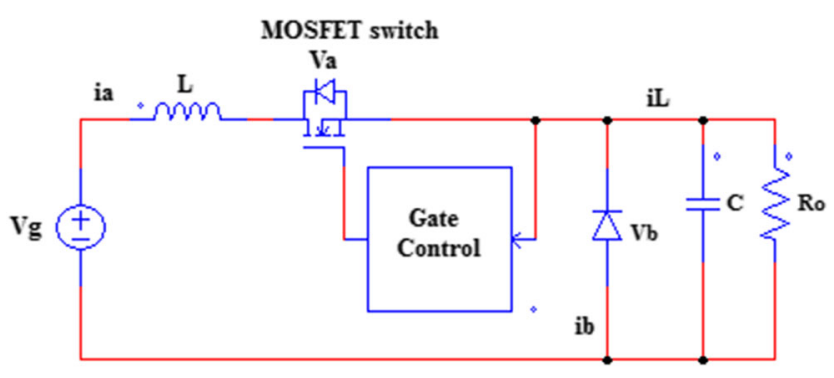

Fig. 3 MOSFET switch representation [22]

\section{Capacitor Design}

The parallel connected capacitors to the rectifier input side can be calculated using Eq. 2 [22].

$C=\frac{I_{\text {out }} \times D}{f_{s} \times \Delta V_{\text {out }}}$

The total capacitor value can be obtained to $208 \mu F$ to meet the system filter specifications. The inductor and capacitor have been designed to decrease the rectifier input current and voltage ripples, such that it will affect the output current and voltage wave forms.

\section{Switching Losses}

It is a loss of power that occurs instantaneously during ONOFF transitions of a semiconductor switch. Although the ON- OFF transition is a few of nanoseconds but, power loss may be considerable amount. From Fig. 3.

$i_{a}(t)+i_{b}(t)=i_{L}(t)$

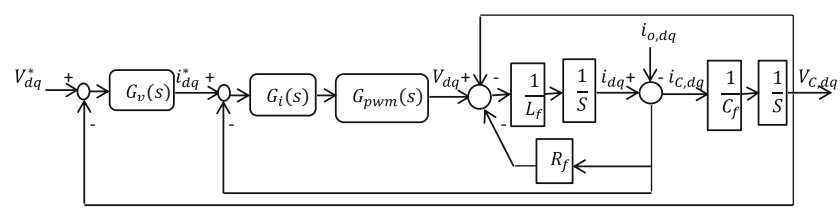

Fig. 5 Closed loop current controller, a d-axis controller b q-axis controller

The instantaneous power dissipated by the transistor can be given by:

$v_{a}(t) \times i_{a}(t)$

When the transistor is in OFF state the energy loss is given by:

$W_{O F F}=0.5 \times V_{g} \times i_{L}\left(t_{2}-t_{0}\right)$,

When $v_{a}=V_{g}$, then the diode becomes forward biased and when the transistor is in ON state the energy loss can be given by:

$W_{O N}=0.5 \times V_{g} \times i_{L}$

The total energy will be dissipated during switching period $W_{O N}+W_{O F F}$

$P_{s w}=\left(W_{O N}+W_{O F F}\right) \times f_{s w}$

\section{Efficiency Versus Switching Frequency}

Electrical system efficiency is given by Eq. 8 .

$\eta=\frac{P_{\text {out }}}{P_{\text {out }}+P_{\text {loss }}}$
Fig. 4 Graphical scheme of the current-control in a dq-frame

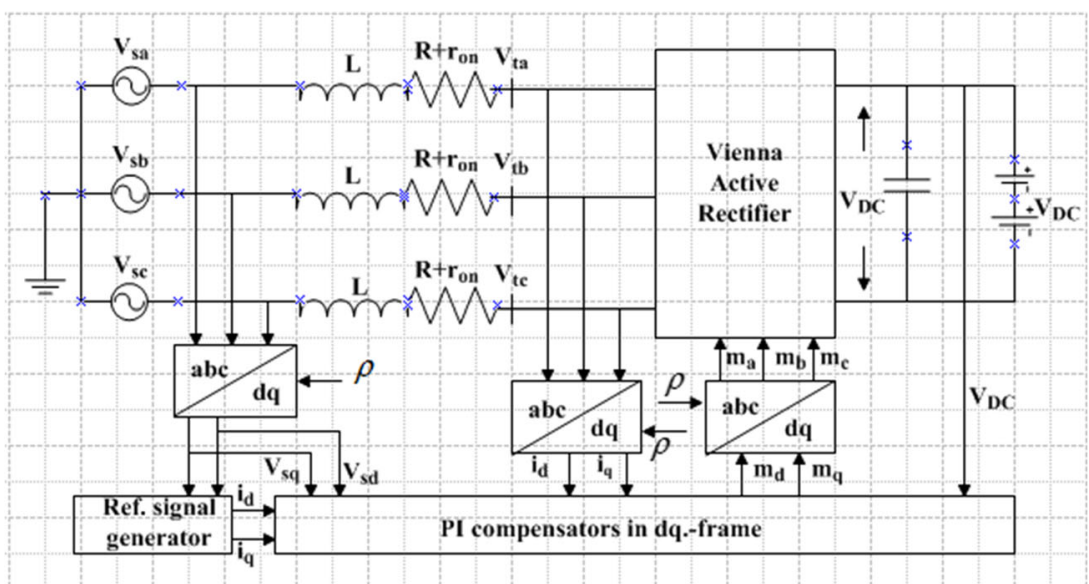


Where $\eta$ is the electrical system efficiency and losses are given by Eq. 9 .

$$
P_{\text {loss }}=P_{\text {cond. }}+P_{\text {fixed }}+P_{s w}
$$

Where $P_{\text {cond }}$. is conduction losses, $P_{\text {fixed }}$ is fixed losses and $P_{s w}$ is switching losses

$P_{s w}=W_{\text {total }} \times f_{s w}$

$W_{\text {total }}=W_{O N}+W_{O F F}$

$P_{s w} \propto f_{s w}$

The critical frequency can be given by,

$$
f_{\text {cri. }}=\frac{P_{\text {cond. }}+P_{\text {fixed }} \text {. }}{W_{\text {total }}}
$$

Switching losses cause the efficiency to decrease at high frequencies, and the Vienna active rectifier has a minimum number of switches comparing with other types of active rectifiers.

\section{Design Criteria of the Rectifier Controller}

The controller aims to ensure constant output voltage and current, and the governor of the control circuit is an output

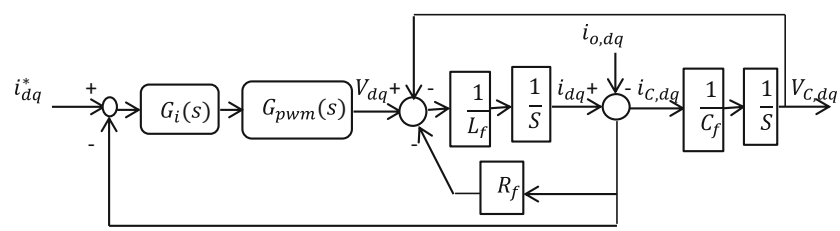

Fig. 7 Block diagram of the designed current loop system

voltage and sinusoidal supply input current, the output voltage is sensed and subtracted from the reference voltage to produce the error signal. It is desirable to minimize the error signal, and the current reference is used to maintain the supply sinusoidal current.

\section{Current Loop Controller Design and Analysis}

The AC voltages in a rectifier system shown in Fig. 4, can be written as [21, 23-26]

$$
\begin{aligned}
& V_{s a}(t)=\hat{V}_{s} \cos \left(\omega_{0} t+\theta_{0}\right) \\
& V_{s b}(t)=\hat{V}_{s} \cos \left(\omega_{0} t+\theta_{0}-\frac{2 \pi}{3}\right) \\
& V_{s c}(t)=\hat{V}_{s} \cos \left(\omega_{0} t+\theta_{0}-\frac{4 \pi}{3}\right)
\end{aligned}
$$

Fig. 6 Block diagram of the closed loop system

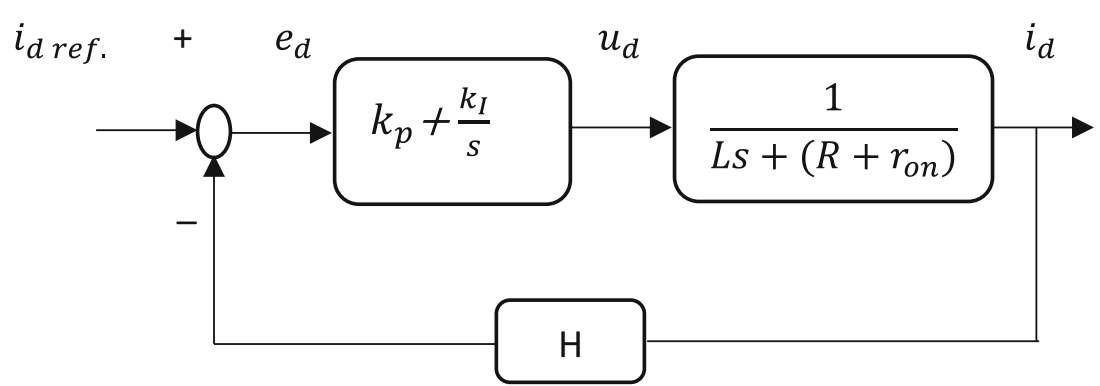

(a)

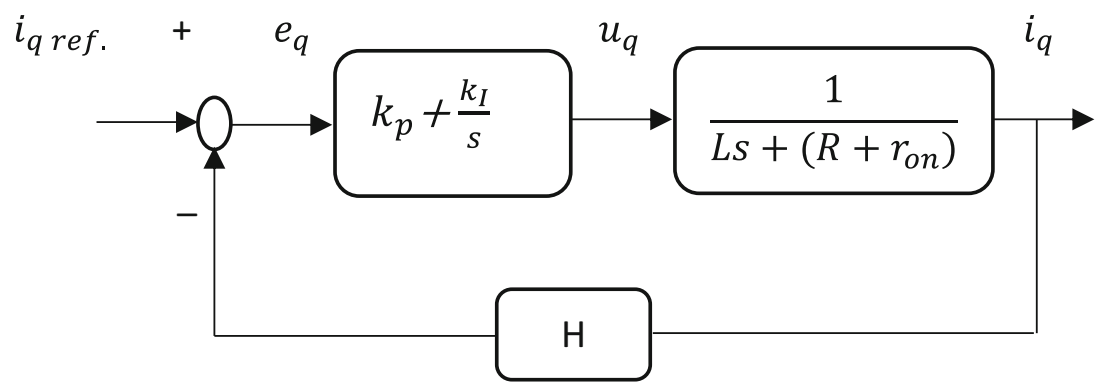

(b) 
Fig. 8 Closed loop FR of the inner current loop

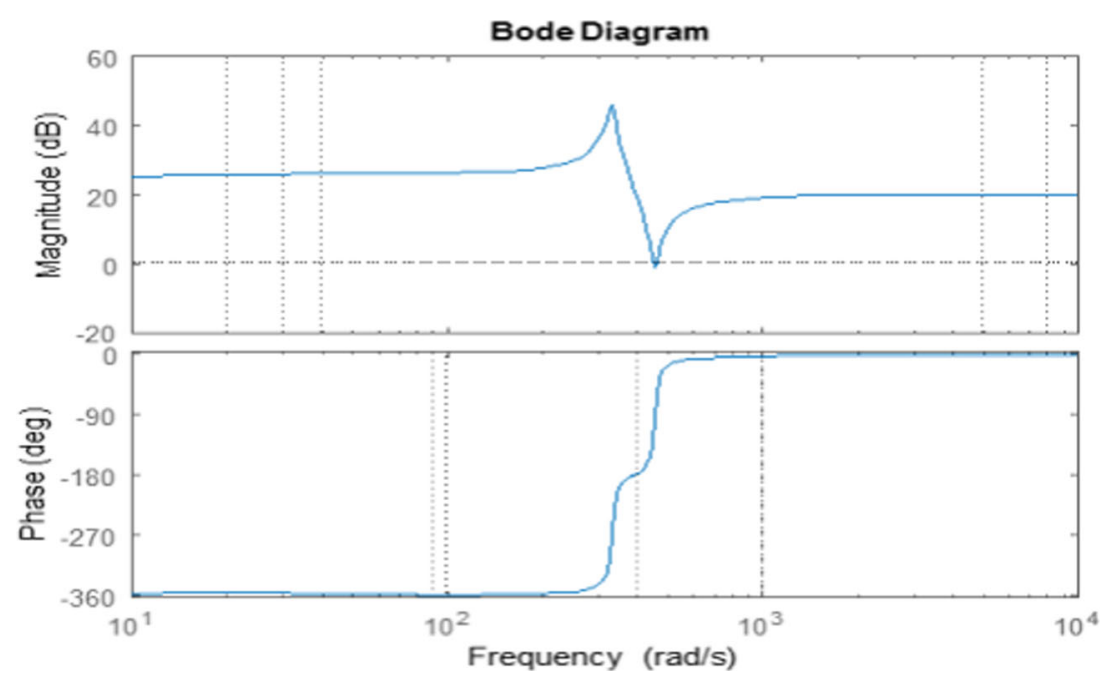

Where $\hat{V}_{s}$ is the peak value of phase voltage, $\omega_{0}$ is the AC source frequency and $\theta_{0}$ is the initial rotor angle. The nonlinear system in Fig. 4, can be described by:

$L \frac{d i_{d}}{d t}=V_{t d}+L \omega(t) i_{q}-\hat{V}_{s} \cos \left(\omega_{0} t+\theta_{0}-\rho\right)-\left(R+r_{o n}\right) i_{d}$

$L \frac{d i_{q}}{d t}=V_{t q}-L \omega(t) i_{d}-\hat{V}_{s} \sin \left(\omega_{0} t+\theta_{0}-\rho\right)-\left(R+r_{o n}\right) i_{q}$

Where $i_{d}, i_{q}$ and $\rho$ are the state variables. $V_{t d}, V_{t q}$ and $\omega$ are the control inputs.

Assume steady state operating conditions and substitute for $\omega(t)=\omega_{0}$, then Eqs. 14 and 15 can be written as:

$L \frac{d i_{d}}{d t}=V_{t d}+L \omega_{0} i_{q}-\left(R+r_{o n}\right) i_{d}-V_{s d}$

$L \frac{d i_{q}}{d t}=V_{t q}-L \omega_{0} i_{d}-\left(R+r_{o n}\right) i_{q}-V_{s q}$
Where $V_{s d}$ and $V_{s q}$ are disturbance inputs. The relationship between a modulating signal and the corresponding AC side terminal voltage can be given by:

$$
\begin{aligned}
& \vec{V}_{t}(t)=\frac{V_{D C}}{2} \vec{m}(t) \\
& V_{t d}(t)=\frac{V_{D C}}{2} m_{d}(t)
\end{aligned}
$$

$V_{t q}(t)=\frac{V_{D C}}{2} m_{q}(t)$

$m_{d}=\frac{2}{V_{D C}}\left(V_{s d}+U_{d}-L \omega_{0} i_{q}\right)$

$m_{q}=\frac{2}{V_{D C}}\left(V_{s q}+U_{q}+L \omega_{0} i_{d}\right)$

Where $U_{d}$ and $U_{q}$ are control inputs. By substituting for the $m_{d}$ and $m_{q}$ from Eqs. 21 and 22 in Eqs. 19 and 20, yields

$V_{t d}(t)=\left(V_{s d}+U_{d}-L \omega_{0} i_{q}\right)$

$V_{t q}(t)=\left(V_{s q}+U_{q}-L \omega_{0} i_{d}\right)$
Fig. 9 Graphical representation of the voltage-control in a dq-frame

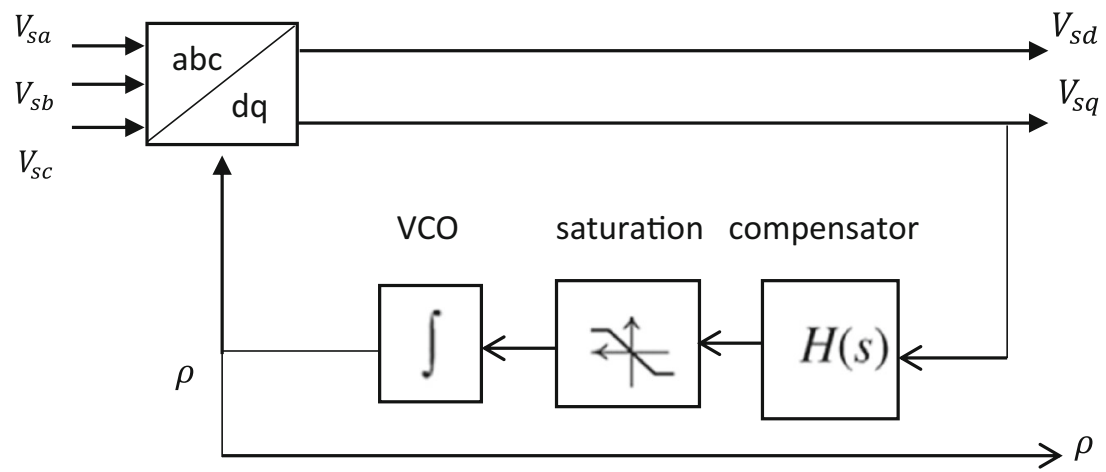


Also by substitute $V_{t d}(t)$ and $V_{t q}(t)$ Eqs. 23 and 24, respectively in Eq. 16 and 17, yields:

$L \frac{d i_{d}}{d t}=U_{d}-\left(R+r_{o n}\right) i_{d}$

$L \frac{d i_{q}}{d t}=U_{q}-\left(R+r_{o n}\right) i_{q}$

Then, Eqs. 25 and 26 depict two separated first order linear systems; $i_{d}$ and $i_{q}$ can be controlled by $U_{d}$ and $U_{q}$, respectively, as shown in Fig. 5a and b.

The voltage loop controls the converter output voltage by fixing the current reference and the current loop is controlling the converter to track the command, [23]. The control block diagram of the closed loop system is clarified in Fig. 6.

Where $G_{v}(\mathrm{~s})$ and $G_{i}(\mathrm{~s})$ and are the voltage and current compensators respectively, $V_{d q}^{*}$ and $i_{d q}^{*}$ are the reference voltage and current vectors, $L_{f}$ is the filter inductor, $R_{f}$ is the equivalent series resistance of the inductor, $C_{f}$ is the filter capacitor value. $G_{p w m}(s)$ is the transfer function related to PWM delays, and $=\left[1-\left(T_{d} / 2\right)\right] /\left[1+\left(T_{d} / 2\right) s\right]$, where $T_{d}$ is the delay time of the system and $=1.5 \mathrm{Ts}=$ $375 \mu s$.

The current compensator $G_{i}(\mathrm{~s})$ that was designed and analysed is proportional resonance PR compensator and can be given using this equation:

$G_{i}(\mathrm{~s})=k_{p}+\frac{2 \omega_{c 1} k_{i} S}{S^{2}+2 \omega_{c 1} S+\left(h \omega_{0}\right)^{2}}$

Where, $k_{p}=2 \pi f_{b w} L$ and $k_{i}=\frac{R_{f}}{L_{f}} k_{p}, f_{b w}$ assumed to be $600 \mathrm{~Hz}, \omega o=2 \pi 60=377 \mathrm{rad} / \mathrm{s}$ is the fundamental resonant frequency, $\omega_{C 1}$ is a damping frequency and
Table 2 Parameters used for compensator design

\begin{tabular}{lll}
\hline Parameter & Description & Value \\
\hline Phase margin & $\delta_{m}$ & 60 \\
Crossover frequency & $\omega_{c}$ & $250 \mathrm{rad} / \mathrm{s}$ \\
Supply frequency & $\omega_{0}$ & $377 \mathrm{rad} / \mathrm{s}$ \\
Peak value of phase voltage & $\hat{V}_{s}$ & $577 \mathrm{~V}$ \\
\hline
\end{tabular}

assumed to be $10 \mathrm{rad} / \mathrm{s}$. The current closed-loop transfer function (TF) Fig. 7, can be determined in Eq. 28

$$
\begin{aligned}
i_{d q}(s)= & \frac{G_{i}(s) G_{p w m}(s) C_{f}(s)}{L_{f} C_{f} S^{2}+R_{f} C_{f} S+G_{i}(s) G_{p w m}(s) C_{f} S+1} i_{d q}^{*} \\
& +\frac{1}{L_{f} C_{f} S^{2}+R_{f} C_{f} S+G_{i}(s) G_{p w m}(s) C_{f} S+1} i_{0, d q}
\end{aligned}
$$

Figure 8 shows the frequency response (FR) of the TF in Eq. 28. The controller has ability to produce zero steadystate error at the desired frequency $(600 \mathrm{~Hz})$ which is affected by the proportional gain.

\section{Voltage-Mode Control Using Phase Locked Loop (PLL)}

The AC voltages (13) in a rectifier system shown in Figs. 5 and 9 , can be rewritten again as:

$$
\begin{aligned}
& V_{s a}(t)=\hat{V}_{s} \cos \left(\omega_{0} t+\theta_{0}\right) \\
& V_{s b}(t)=\hat{V}_{s} \cos \left(\omega_{0} t+\theta_{0}-\frac{2 \pi}{3}\right) \\
& V_{s c}(t)=\hat{V}_{s} \cos \left(\omega_{0} t+\theta_{0}-\frac{4 \pi}{3}\right)
\end{aligned}
$$

Fig. 10 The frequency response of the PLL for the loop gain L(s)

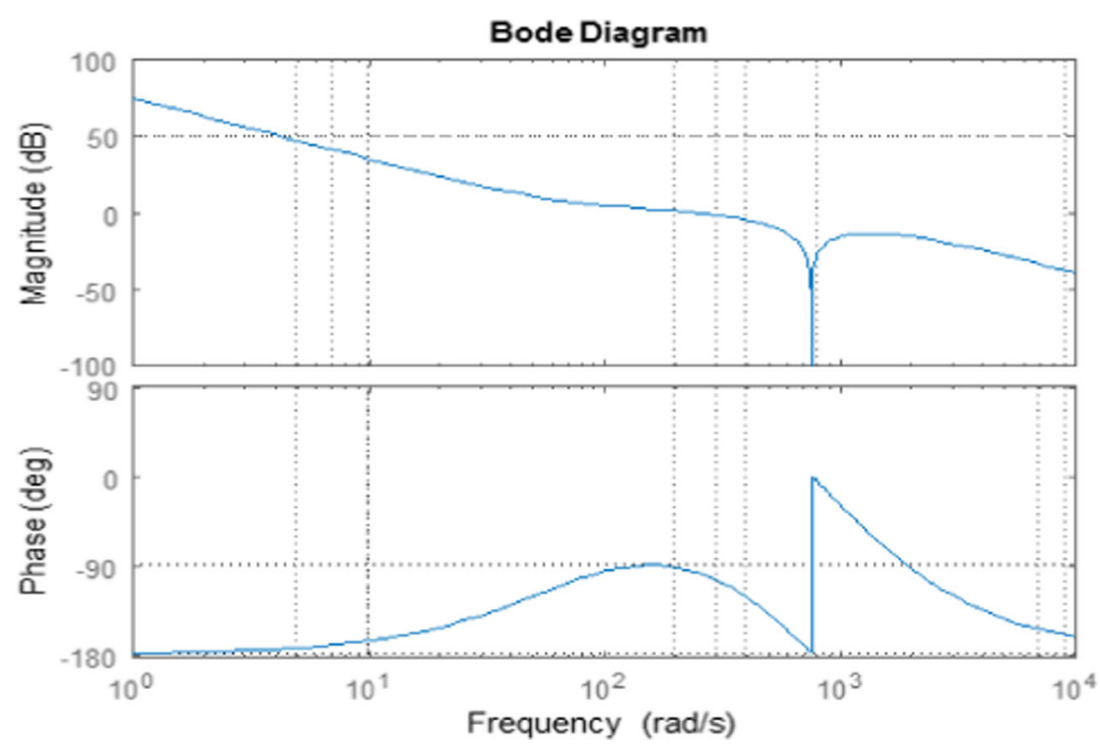


Based on the space phasor

$f_{d}+j f_{q}=\vec{f}(t) e^{-j \rho(t)}$

The voltage expressed in a dq-frame can be given by

$V_{s d}=\hat{V}_{s} \cos \left(\omega_{0} t+\theta_{0}-\rho\right)$

$V_{s q}=\hat{V}_{s} \sin \left(\omega_{0} t+\theta_{0}-\rho\right)$

Where $\rho$ is the phase shift and,

$\frac{\partial \rho}{\partial t}=\omega(t)$

From Eq. 33, $\omega(t)$ is the input to the voltage controlled oscillator (VCO) as shown in Fig. 9, and it is integrated to produce the desired value of $\rho$.

The compensator output equation can be formulated as,

$\omega(t)=H(p) V_{s q}(t)$

Where $H(p)$ is a compensator transfer function and $p$ is a differentiation operator

The PLL compensator H(s) in Fig. 10, can be formulated as,

$H(s)=\left(\frac{h}{\hat{V}_{s n}}\right) \times \frac{S^{2}+\left(2 \omega_{0}\right)^{2}}{S\left(S+2 \omega_{0}\right)^{2}} \times F(s)$

Fig. 11 Connection of three units and the controller, a Three units connected in parallel and the fault and fault blocking diode are placed at unit $1, \mathbf{b}$ FRT controller
Table 3 Parameters used for simulation

\begin{tabular}{lll}
\hline Parameter & Description & Value \\
\hline Generator voltage rating & $V_{g}$ & $500 \mathrm{~V}$ \\
Generator current rating & $I_{g}$ & $20 \mathrm{~A}$ \\
Turbine voltage rating & $V_{t}$ & $500 \mathrm{~V}$ \\
Turbine current rating & $I_{t}$ & $20 \mathrm{~A}$ \\
Generator filter capacitance & $C_{F}$ & $208 \mu F$ \\
Generator filter inductance & $L_{F}$ & $82 \mathrm{mH}$ \\
DC link capacitance & $C_{1}, C_{2}$ & $1000 \mu F$ \\
Load & $\mathrm{R}$ & $50 \Omega$ \\
\hline
\end{tabular}

Where $\hat{V}_{s n}$ is the nominal value of $\hat{V}_{s}$, h is a constant gain, $\mathrm{F}(\mathrm{s})$ is a convenient transfer function with no zero at $\mathrm{S}=0$, and can be obtained using the Eq. 36 .

$F(s)=\left(\frac{S+\left(p_{1} / \alpha\right)}{S+p_{1}}\right)^{2}$

Where $p_{1}$ is the filter pole, $\alpha$ is a real constant and should be greater than 1 . The maximum phase margin of the filter is given by Eq. 37 .

$\delta_{m}=\sin ^{-1}\left(\frac{\alpha-1}{\alpha+1}\right)$

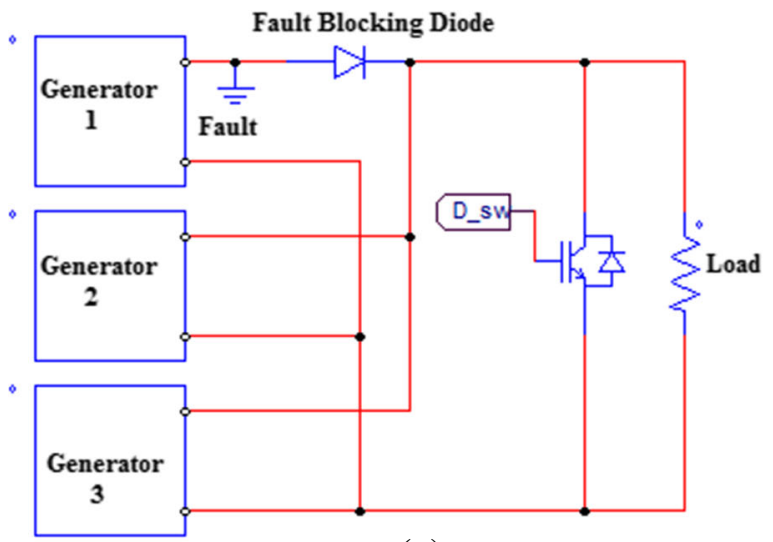

(a)

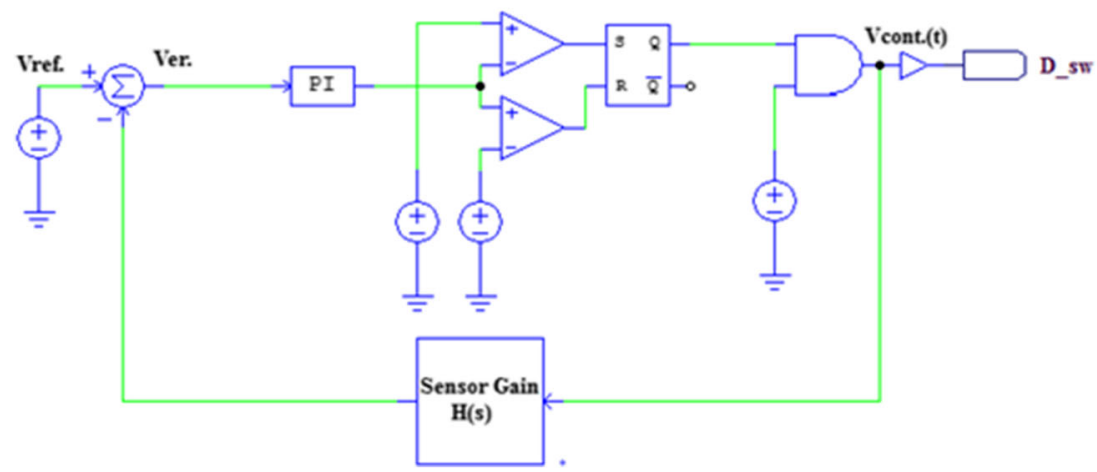

(b) 
The maximum phase margin takes place at the frequency given by Eq. 38 .

$\omega_{m}=\frac{p_{1}}{\sqrt{ } \alpha}$

$\omega_{m}$ can be equal to the crossover frequency $\omega_{c}$. The loop gain can be solved using the equation,

$l(s)=h \times \frac{S^{2}+\left(2 \omega_{0}\right)^{2}}{S^{2}\left(s+2 \omega_{0}\right)^{2}} \times F(s)$

Assume $\mathrm{L}(\mathrm{s})=1$, and substitute for $\mathrm{h}$, then $\mathrm{h}=1.09 \times 10^{6}$. Using parameters given in Table 2, the loop gain can be got and plots to determine the frequency response.
From the bode plot Fig. 10, it is found that $\mathrm{L}(\mathrm{s})$ declines with the slope of $-20 \mathrm{~dB}$ when $\omega$ is greater than $\omega_{C}$. The gain margin and the phase margin are $75 \mathrm{~dB}$ and $90^{\circ}$ respectively, which is indication of a good stability.

\section{Fault Effect Elimination and Analysis}

The wind power plant consists of three parallel connected WECUs as shown in Fig. 11a. DC fault that occurs close to unit 1 terminal will cause large fault currents in its proximity. This type of fault is due to loss or short circuit of one transmission line. The fault is considered to be on DClink connected to unit 1 as shown in Fig. 11a, the output

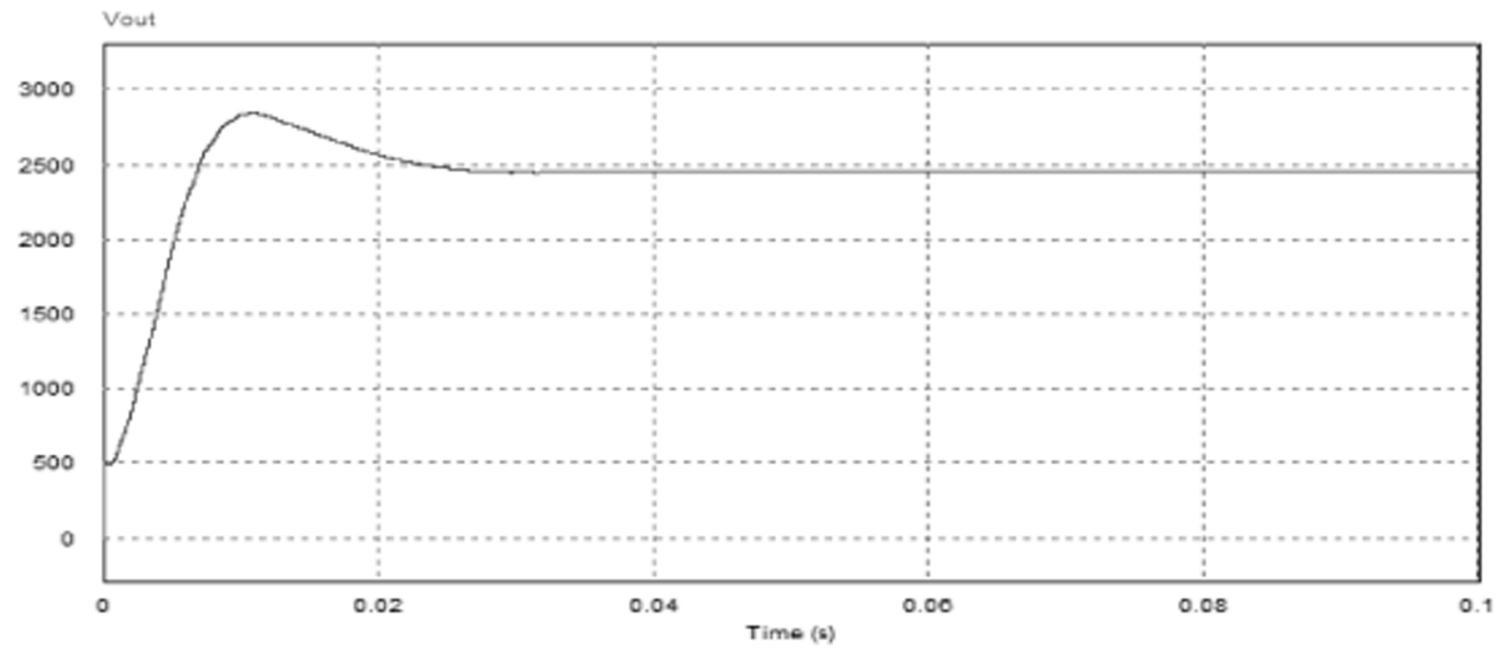

(a)

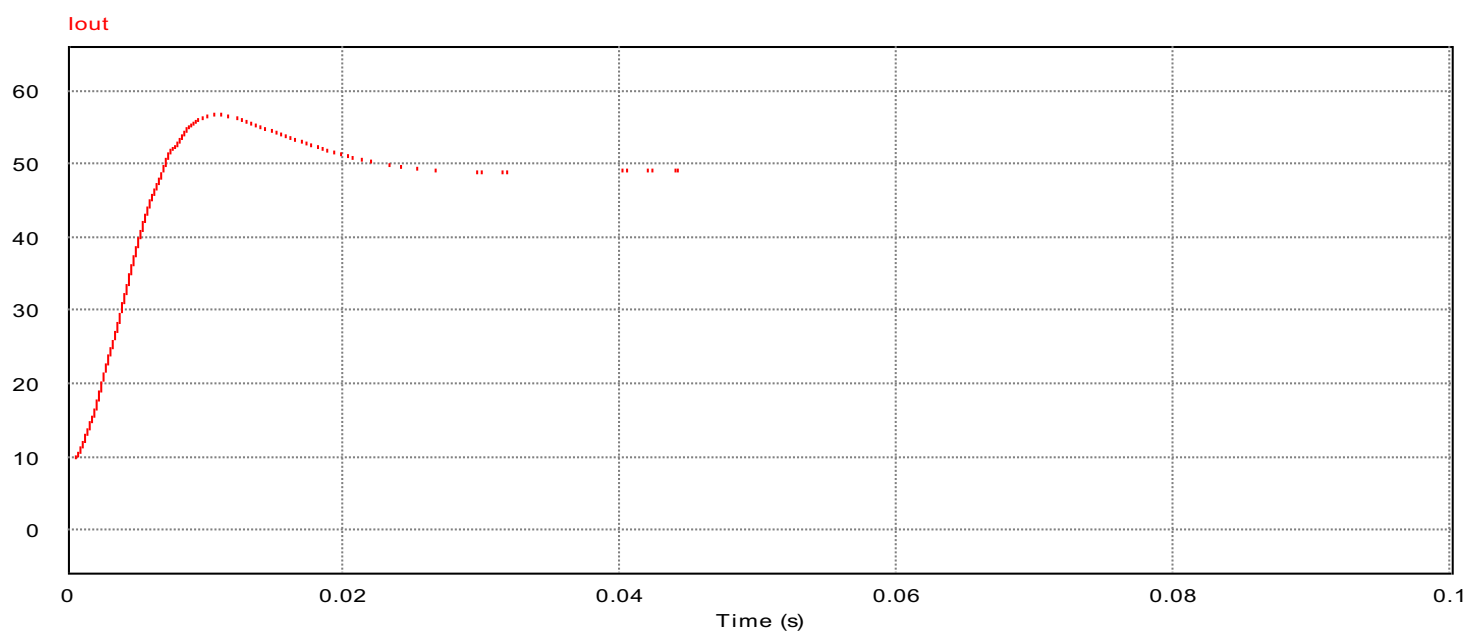

(b)

Fig. 12 Steady state operation, voltage and current wave forms, a output voltage, b output current 
current will be zero due to the flow of the fault current through the system. Figure 11b, shows the controller that has been used to ride through the fault through D_sw and the fault blocking diode which blocks the fault by reverse bias and FRT components.

The controller output voltage $\mathrm{V}_{\text {cont. }}(\mathrm{t})$ is sensed with $\mathrm{H}(\mathrm{s})$, the sensor output will be $\mathrm{H}(\mathrm{s}) \times \mathrm{V}_{\text {cont. }}(\mathrm{s})$ and is compared with a reference input voltage $\mathrm{V}_{\text {ref., }}$ the aim is to let $\mathrm{H}(\mathrm{s}) \times \mathrm{V}_{\text {cont. }}(\mathrm{s})$ closer to $\mathrm{V}_{\text {ref }}$. The variation between the reference input $\mathrm{V}_{\text {ref. }}$, and the sensor output $\mathrm{H}(\mathrm{s}) \times \mathrm{V}_{\text {out }}(\mathrm{s})$ is an error signal. If the feedback system is perfect then the error signal will be zero. In practice, the error signal is commonly not zero but none the less very small. In any case of disturbance the compensator should compensate the error signal to the desired signal.

\section{Simulation Results and Discussions}

Simulations have been carried out using PSIM programme and the values of parameters used have been shown in Table 3. Three WECUs are connected in parallel, so that the parallel connection is the strongest type of connections and if one unit collapses the system remains in synchronism.

In normal operation conditions, the switch will be locked for a long time, so that voltage and current waves are in stable operation. Figure 12a and b, shows the output voltage and current wave forms in the steady state operation. The output voltage as shown in Fig. 12 is in steady state condition and is stable at $2400 \mathrm{~V}$ after small overshooting due to system start up.

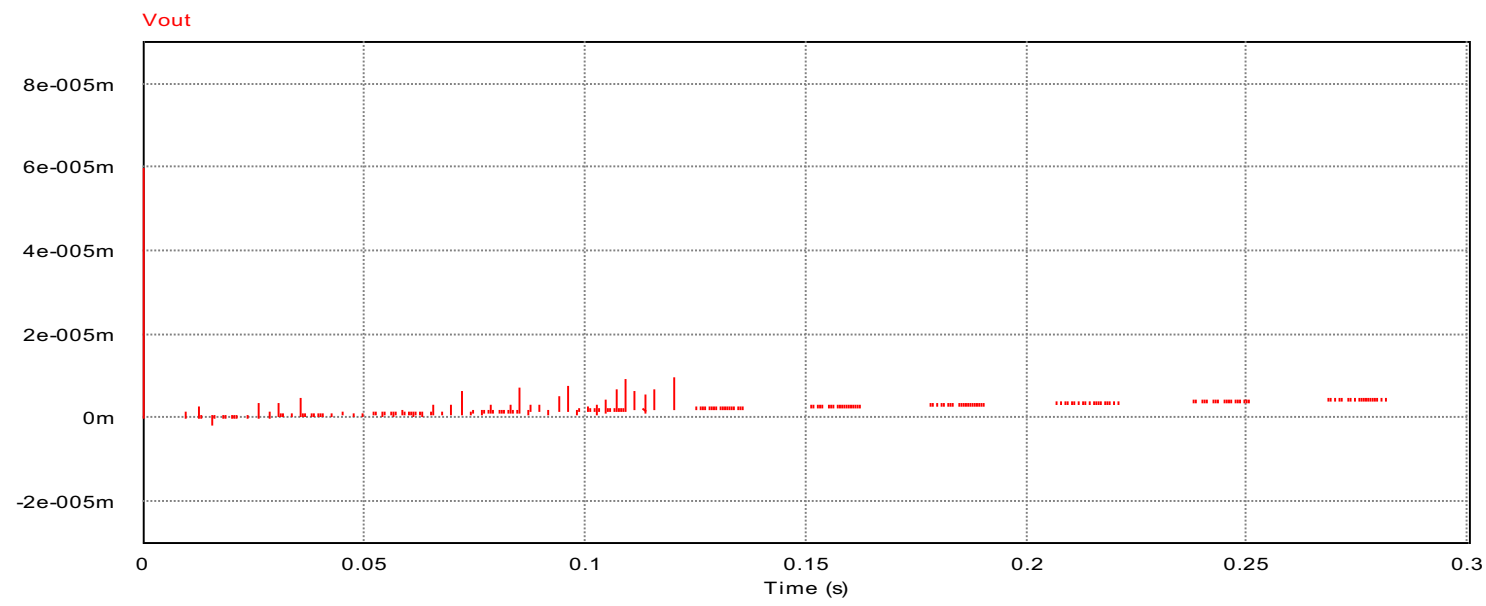

(a)

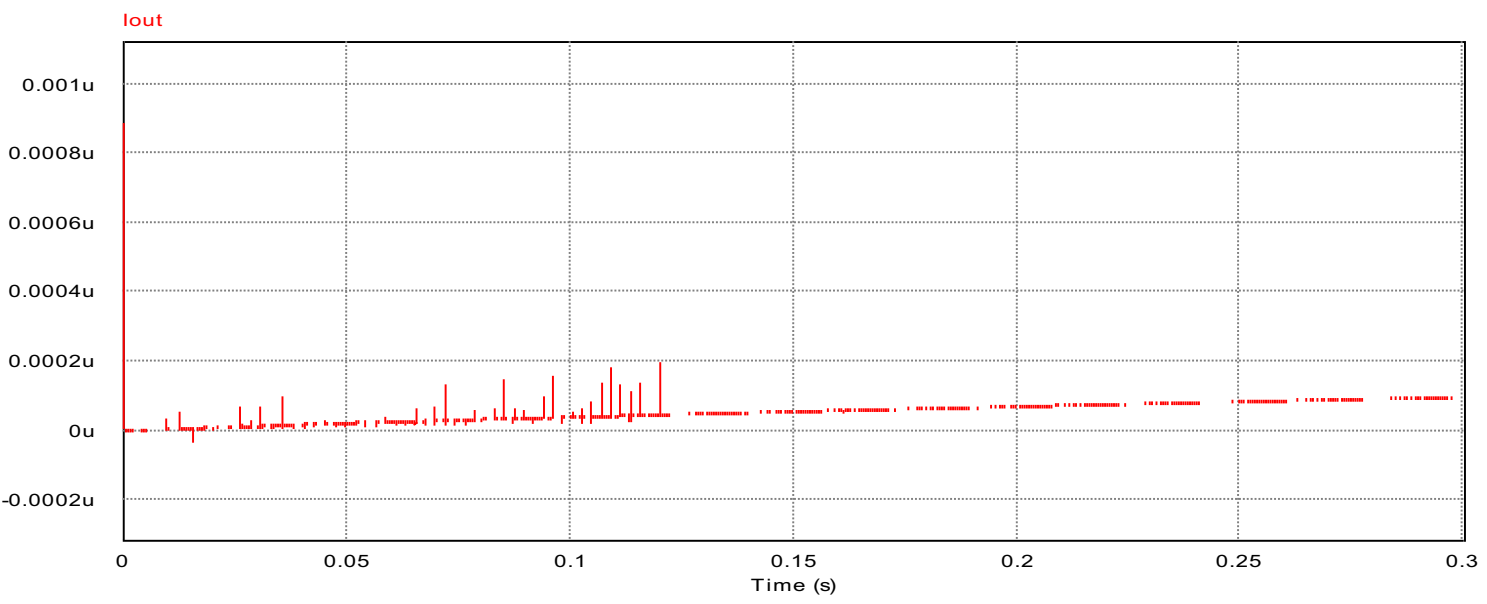

(b)

Fig. 13 Output voltage and current wave forms when applying the fault, a output voltage, $\mathbf{b}$ output current 
Similar to output voltage, the output current as shown in Fig. 12b, is in a normal operation and stable at $50 \mathrm{~A}$ after some overshooting. The collapsed output voltage and current wave forms which represent the faulted system are shown in Fig. 13a and b, when the fault applied in unit 1, the fault current will flow through the system and will result of a damage, but by connecting the controller that has been designed the fault can ride through, as shown in Fig. 14.

Figure 14, shows the output voltage and current wave forms after applying FRT controller the fault blocking diode, and simulation result shows that the controller can ride through the fault very well, because the output voltage and current wave forms are similar as steady state operation "before applying the fault". The voltage across the fault blocking diode shown in Fig. 15a has the same peak inverse value of load voltage, and the current wave Fig. 15b has zero value because of diode reverse bias.
Howell et al. [27] they did a similar work of using a fault blocking diode in a DC transmission line to block the fault current and they built a HVDC system topology to transmit unidirectional power into weak AC system while retaining the ability to clear DC faults. They discussed Control strategies including fault blocking diode and its performances under DC and AC faults using electromagnetic transient simulations, and they concluded that the topology is viable candidate. The difference between this work and their work is they used a line commutated converter LCC and a modular multilevel converter MMC as a rotor side converter RSC and a grid side converter GSC, respectively. Furthermore, this control strategy using fault blocking diode was performed in [28-32] and they concluded and recommended that it is a practical and effective controller that participate in the power system stability.

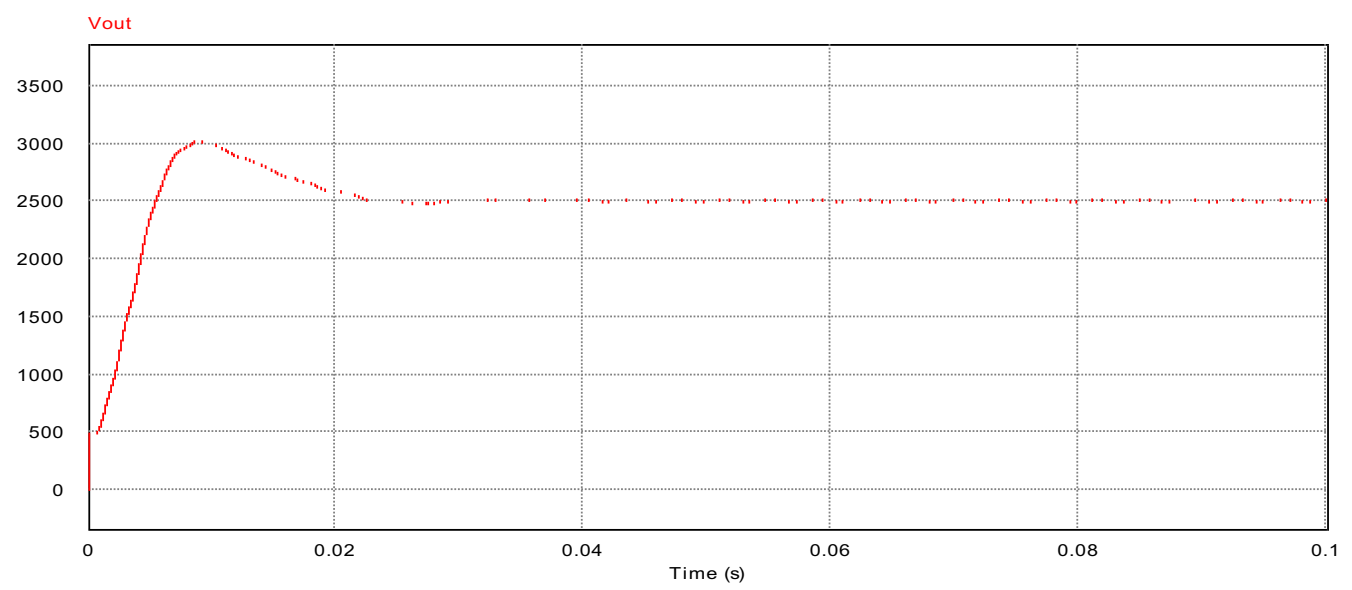

(a)

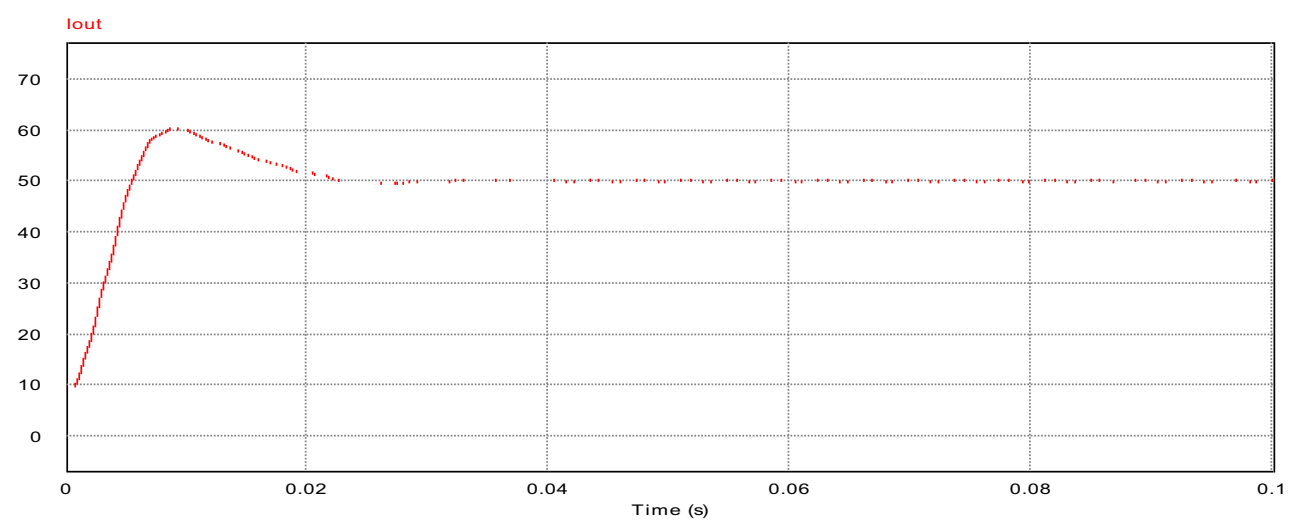

(b)

Fig. 14 Output voltage and current wave forms when applying FRT controller, a output voltage, b output current 


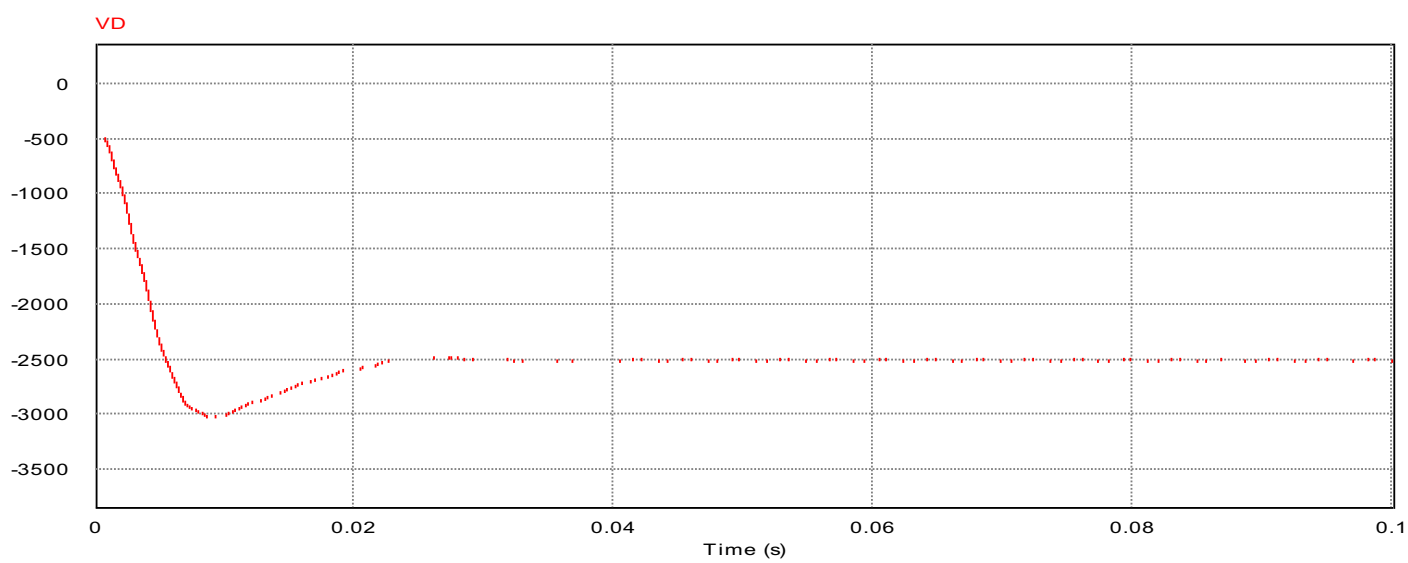

(a)

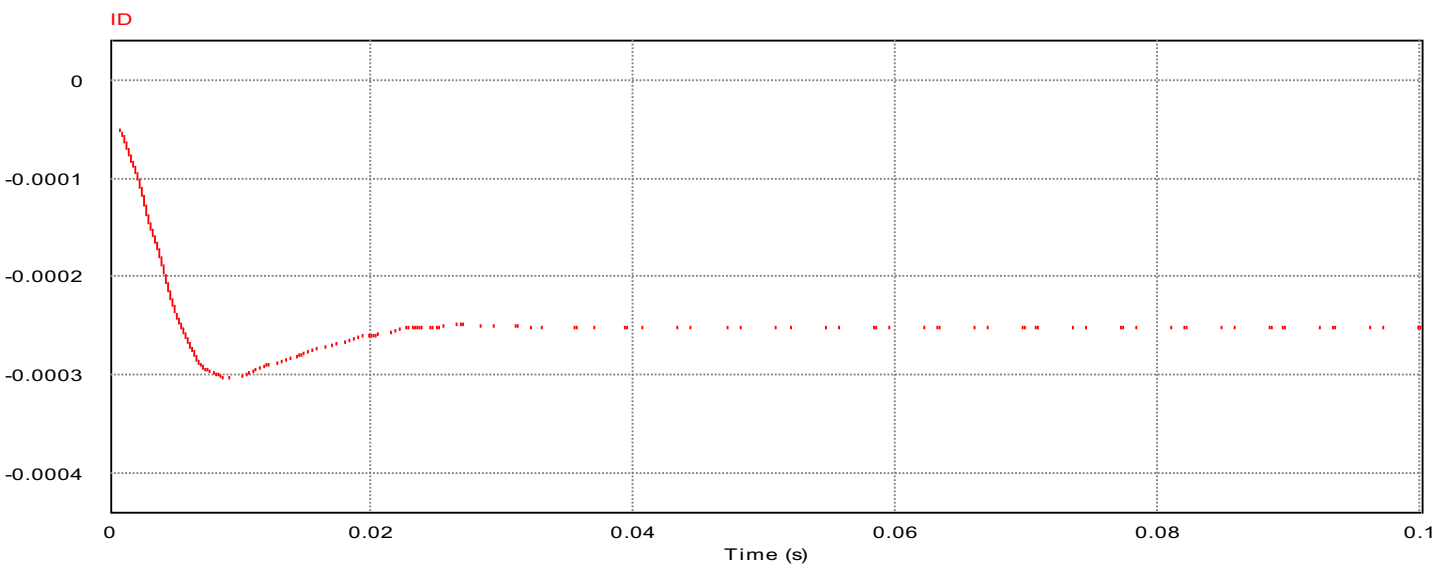

(b)

Fig. 15 Fault blocking diode characteristics, a voltage characteristics $\mathbf{b}$ current characteristics

\section{Conclusion}

This paper has presented DC-link fault analysis to ride through the transient faults. The simulation results have shown the superiority of the proposed FRT capability controller, which involving sub-models consisting of controller and fault blocking diode. The fault blocking diode has detected the fault very fast and protected power tools from thermal over stresses with the controller assistance by creating new current path to eliminate the fault current effect. This paper proved that the unidirectional HVDC scheme is able to protect the transmission DC line from the transient faults that can occur due to short circuit. The current and voltage loop controllers have been designed to maintain constant voltage at steady state conditions. Also, the supply side filter that consists of inductor and capacitor has been designed to decrease the input voltage and current ripple values It has been concluded that the power transmission is found to be rapid and continual for the non-permanent faults and the controller has improved the stability and reliability of the wind power HVDC system.

\section{References}

1. Sahoo SS, Roy A, Chatterjee K (2016) Fault ride-through enhancement of wind energy conversion system adopting a mechanical controller. In: National power systems conference (NPSC). Bhubaneswar, pp 1-5

2. Chitti Babu B, Mohanty KB (2017) Experimental validation of improved control strategy of grid-interactive power converter for wind power system. Technol Econ Smart Grids Sustain Energy 2(5):1-12

3. Praveen T, Munish M, Pidanic J et al (2017) A review on microgrid based on hybrid renewable energy sources in southasian perspective. Technol Econ Smart Grids Sustain Energy 2(10): $1-16$ 
4. Chen L, Dai Y, Min Y et al (2015) Study on the mechanism of transient voltage stability of wind power with power electronic interface. In: Asia-pacific power and energy engineering conference. Brisbane, pp 1-5

5. Tan J, Zhang Y (2017) Coordinated control strategy of a battery energy storage system to support a wind power plant providing multi-timescale frequency ancillary services. IEEE Trans Sustain Energy 8(3):1140-1153

6. Chaudhary SK, Teodorescu R, Rodriguez P et al (2009) Chopper controlled resistors in VSC-HVDC transmission for wpp with fullscale converters. In: IEEE sustainable alternative energy (SAE) conference. Valencia, pp 1-8

7. Ding X, Qian Z, Xie Y et al (2005) Three-phase z-source rectifier. In: 36th power electronics specialists conference. Recife, pp 494 500

8. Wang S, Chen N, Yu D et al (2015) Flexible fault ride through strategy for wind farm clusters in power systems with high wind power penetration. Energy Convers Manag 93:239-248

9. Gevorgian V, Zhang Y, Ela E (2015) Investigating the impacts of wind generation participation in interconnection frequency response. IEEE Trans Sustain Energy 6:1004-1012

10. Kolar JW, Round SD, Karutz P, Heldwein ML (2007) Towards a $30 \mathrm{~kW} /$ liter, three phase unity power factor rectifier. In: Power conversion conference. Nagoya, pp 1251-1259

11. Swain S, Ray PK (2016) Short circuit fault analysis in a grid connected DFIG based wind energy system with active crowbar protection circuit for ridethrough capability and power quality improvement. Int J Electric Power Energy Syst 84:64-75

12. Gkavanoudis SI, Demoulias CS (2013) A combined fault ridethrough and power smoothing control method for full-converter wind turbines employing supercapacitor energy storage system. Electr Power Syst Res 106:62-72

13. Lai R, Wang F, Burgos R et al (2008) A systematic topology evaluation methodology for high-density three-phase PWM ACAC converters. IEEE Trans Power Electron 23(6):2665-2680

14. Yaramasu V, Wu B (2014) Predictive control of a three-level boost converter and an NPC inverter for high-power pmsg-based medium voltage wind energy conversion systems. IEEE Trans Power Electron 29(10):5308-5322

15. Rajaei A, Mohamadian M, Varjani AY (2013) Vienna-rectifierbased direct torque control of PMSG for wind energy application. IEEE Trans Ind Electron 60(7):2919-2929

16. Gao T, Zhang S, Zhang $S$ et al (2017) A dynamic model and modified one-cycle control of three-level front-end rectifier for neutral point voltage balance. IEEE J Mag 5:2000-2010

17. Thangavelu T, Shanmugam P, Raj K (2015) Modelling and control of VIENNA rectifier a single phase approach. IET Power Electron 8(12):2471-2482

18. Le Claire JC, Le Borgne G (2008) Double boost effect topology for ac/dc converter with unity power factor. In: IEEE power electronics specialists conference. Rhodes, pp 3199-3205
19. Teshnizi HM, Moallem A, Zolghadri MR et al (2008) A dualframe hybrid vector control of vector-modulated VIENNA I rectifier for unity power factor operation under unbalanced mains condition. In: Applied power electronics conference and exposition. Austin, pp 1402-1408

20. Jiang X, Yang J, Han J et al (2014) A survey of cascaded multilevel PWM rectifier with VIENNA modules for HVDC system. In: Power electronics and application conference and exposition. Shanghai, pp 72-77

21. Hang L, Zhang H, Liu S et al (2015) A novel control strategy based on natural frame for Vienna-Type rectifier under light unbalanced-grid conditions. IEEE Trans Ind Electron 62(3):13531362

22. Erickson RW (2000) Switch realization. In: Fundamentals of power electronics, 2nd edn. Secaucus, Kluwer Academic Publishers, New York. Boston, chap 4, pp 63-101, chap 10, pp 377-400

23. Yazdani A, Iravani R (2010) Voltage-sourced converters in power systems, chap 8. Wiley, Hoboken, pp 204-244

24. Adhikari J, Prasanna IV, Panda SK (2016) Voltage oriented control of the three-level vienna rectifier using vector control method. In: Applied power electronics conference and exposition (APEC). Long Beach, pp 9-16

25. Li X, Liu W, Song Q et al (2013) An enhanced MMC topology with dc fault ride-through capability. In: 39th annual conference of the IEEE Industrial electronics society. Vienna, pp 61826188

26. de Bosio F, Pastorelli M, de Sousa R, Antonio L et al (2015) Current control loop design and analysis based on resonant regulators for micro grid applications. In: Proceedings of the IEEE industrial electronics conference

27. Howell S, Filizadeh S, Gole AM (2017) Unidirectional HVDC topology with DC fault ride-through capability. Can J Electr Comput Eng 40(1):41-49

28. Zhang J, Zhao C (2015) The research of SM topology with DC fault tolerance in MMC-HVDC. IEEE Trans Power Delivery 30(3):1561-1568

29. Umana A, Meliopoulos A (2016) Detection of cell-level fault conditions within a photovoltaic array system. In: 2016 IEEE/PES transmission and distribution conference and exposition (T\& D). Dallas, pp 1-5

30. Nguyen T, Lee D (2015) A novel submodule topology of MMC for blocking DC-fault currents in HVDC transmission systems. In: 9th international conference on power electronics-ECCE Asia. Seoul, pp 2057-2063

31. Li R, Fletcher J, Xu L, Holliday D, Williams B (2015) A hybrid modular multilevel converter with novel three-level cells for DC fault blocking capability. IEEE Trans Power Delivery 30(4):20172026

32. Zhao Y, Palma J, Mosesian J, Lyons R Jr, Lehman B (2013) Lineline fault analysis and protection challenges in solar photovoltaic arrays. IEEE Trans Power Delivery 60(9):3784-3795 